Boise State University

ScholarWorks

Educational Technology Faculty Publications and

Presentations

Department of Educational Technology

7-1-2014

Establishing an Equitable and Fair Admissions System for an Online Doctoral Program

Ross A. Perkins

Boise State University

Patrick R. Lowenthal

Boise State University 


\title{
Establishing an Equitable and Fair Admissions System for an Online Doctoral Program
}

\author{
Ross A. Perkins \\ Department of Educational Technology \\ Boise State University \\ rossperkins@boisestate.edu \\ Patrick R. Lowenthal \\ Department of Educational Technology \\ Boise State University \\ patricklowenthal@boisestate.edu
}

\begin{abstract}
The field of educational technology has seen marked growth from just a small number of distance-based doctoral programs to nearly 20 today. Creating and sustaining a quality doctoral program of any kind requires a substantial amount of work; the additional challenges of online programs both increases and changes the nature of the efforts required. Among these challenges is creating an admissions process that treats people fairly, does not create a burdensome system for applicants or those involved in the selection process, and ensures the selection of a solid foundation of high quality candidates with whom faculty can mentor, who add value to the program, and who can benefit from the program. This paper explores common admissions requirements among institutions offering a distance or hybrid doctorate in Educational Technology and examines the specific admissions system used by the Department of Educational Technology at Boise State University.
\end{abstract}

\section{Introduction}

A doctoral degree is a highly sought after degree (Lee \& Danby, 2012). Almost 400,000 people are currently pursuing a doctorate (Walker, Golde, Jones, Bueschel, \& Hutchings, 2008) and more than 40,000 doctoral degrees are awarded each year (Golde, 2006) - 15\% of which are in the field of Education (Golde \& Walker, 2006). The number of doctoral programs as well as total graduates has increased over the past 20 years (Mason, 2012). Despite the rising number of doctorates being awarded, though, completing a terminal degree has not been a possibility for those who must contend with competing priorities. Enrolling in a traditional, residency-based, doctoral program is not a viable option for those who must support a family or who have an employment situation that is otherwise satisfactory. For nearly two decades students have been able to enroll in distance-based master's level programs, but generally only non-traditional institutions have been willing to provide opportunities for doctoral programs. Within the last few years, however, institutions with historical, campus-based doctoral programs have begun to offer doctorates that can be completed either entirely online or with very minimal campus or site visits (the latter known as hybrid programs). The advent of these programs means that those interested in pursuing a terminal degree and enrolling at a recognized institution no longer need to leave career and community in order to do so. The flexibility and convenience of distance programs appeals to those with busy schedules or who live in places simply too far for a regular commute to an on-campus program (Stavredes, 2011). With the expansion of learning space for doctoral degrees and the marketing of those opportunities, the number of professionals to whom such programs appeal might increase as well. Program personnel in distance-based doctoral programs must be prepared to meet many challenges, but among the first of them is how to administrate an admissions system that may be facing issues of scalability.

It is important to keep in mind that doctoral programs are different from other graduate programs and are unable to scale in the same manner. For instance, doctoral programs - which rely heavily on one-on-one mentoring - cannot grow at the same rate as other online undergraduate or graduate programs. Traditional doctoral programs also have a much higher dropout rate - nearly 50\% of students who begin a doctoral program do not finish it (Burnett, 1999; Hawley, 2003). This dropout rate might drastically increase for online doctoral programs, as online programs 
themselves suffer from a high drop-out rate as well (Park \& Choi, 2009). Given the amount of work students and faculty must do in a doctoral program, and knowing that persistence and retention is a real issue, program personnel must be conscientious about who is admitted.

The marked increase in the number of applications that online programs receive means that carefully choosing students requires a great deal of time. Systems must be in place to deal with potentially dozens upon dozens of applications (Dawson, Cavanaugh, Sessums, Black, \& Kumar, 2011). These systems and practices must allow each applicant to be treated equitably and, at the same time, give faculty who will advise and build mentoring relationships voice in the selection process. In the following paper, we describe common approaches to admissions among institutions offering doctoral degrees in Educational Technology or a closely related field, we describe Boise State University's program, approach and rationale for admissions, and we conclude by discussing lessons learned.

\section{Admission Requirements at Various Institutions}

We selected 17 institutions, public and private, traditional and non-traditional, to get a sense of how admissions requirements compare among those who offer an Educational Technology doctorate (or a doctorate in a nearly synonymous field) at least in part online. The list of universities was not comprehensive; it was primarily based on the authors' knowledge of existing programs as well as an Internet search of such programs. We discovered that many more application pieces are required by public, campus-based programs than are required by either private or nontraditional (online only) institutions. The pieces required by programs range from relatively simple (an application, names of references, and official transcripts) to those that require the Graduate Record Exam, a writing sample, actual letters of reference, and so on. Despite the different focus that exists in terms of focus (practitioner vs. research intensive), Ed.D. and Ph.D. programs do not seem to have markedly different specifications for their degree programs.

We contend that the more things one can know about a prospective student, the more confident one can be in her or his ability to be the right fit for a given program - an important consideration for both students and faculty members who teach and advise. This perspective, though, means that faculty involved in reviewing applications (in which applicants are required to submit more evidence than transcripts alone) are then obligated to spend more time examining the materials. We next describe what we do in Boise State University's Department of Educational Technology with respect to admissions materials, the rationale for what we require, and how we go about reviewing materials in a manner that tries to be both fair and equitable to all applicants.

\section{The Ed.D. / Educational Technology Program at Boise State University}

The Department of Educational Technology at Boise State University began offering courses online in 1999. Our initial master's degree program now includes two different tracks (a Master of Educational Technology (MET) and a thesis-based Master of Science in Educational Technology (MSET)), as well as three different graduate certificate programs. Over the years, our enrollments have grown exponentially - from a program with a few dozen students to a program with nearly 450 students and close to 800 course enrollments. While the College of Education has an Ed.D. in Curriculum and Instruction (established in 1993) that enables students to do an emphasis in Educational Technology, it is campus-based. Students in the program are limited in the number of online courses they can take, as most core and research courses are only offered on campus.

To meet the needs of the university, which has had a focus on increasing its doctoral offerings, as well as to meet the needs of the community of learners, we created a fully online Doctorate of Education in Educational Technology. The program was approved by the Idaho State Board of Education in 2011 and we enrolled our first cohort in fall 2012. There is great debate about the differences between an Ed.D. and a Ph.D. (see Levine, 2005; Perry \& Imig, 2008; Shulman, Golde, Bueschel, \& Garabedian, 2006), but following the rationale developed by the Carnegie Project on the Education Doctorate (Perry \& Imig, 2010), we see the Ed.D. as a professional practice degree that "prepares one to apply research-based knowledge and to generate contextually based knowledge to improve and advance practice" (Dawson et al., 2011, para. 4). As a program, we specialize in working with emerging technologies and developing practitioners and leaders in the field of Educational Technology.

Our program was intentionally designed to: (a) focus on creating leaders and innovators in Educational Technology, (b) build upon our MET curriculum, and (c) be offered completely online. The program consists of 66 credit hours (see Table 1; a person can transfer up to one-third of the total credit hours required). Students are required to enroll in 
This is an author-produced, peer-reviewed version of this article. The final, definitive version of this document can be found online at TechTrends, published by Springer. Copyright restrictions may apply. doi: 10.1007/s11528-014-0766-1

at least six credits during each of the first four semesters (fall/spring), which is done to ensure that students can graduate within the seven-year window prescribed by Graduate College policy. Students are encouraged to take summer courses if they need electives, but no formal doctoral courses are offered during the summer sessions at this time.

\section{[INSERT TABLE 1 HERE]}

Our plan has been to admit a cohort of between 15 and 20 students into the program every fall for the first three years. Based on anecdotal reports of colleagues offering similar programs, we realized that we should prepare to process dozens of applications from people who were well qualified for doctoral studies. In fact, the majority of our applicants have high profile or prestigious positions. Having a very well qualified pool of applicants is not a problem per se, but it does mean that we are confronted with the challenge of finding the best way to identify students for our program who are the best fit given our mission and faculty areas of focus. Therefore, a year before we offered our first course, we started to develop the best way to manage the entire admissions process. Again, the goals were to treat all applicants equitably and fairly, not to unduly burden faculty, staff or those who apply, and to have a system that would allow us to choose applicants who would most benefit from the kind of program we offer and who, at the same time, would benefit faculty and each other. In the following section, we will describe how we addressed this challenge.

\section{The Admissions Requirements}

Those seeking admission to the Ed.D. in Educational Technology program at Boise State University initiate their application through a web-based form that allows them to apply to the Graduate College ${ }^{1}$ and at the same time apply for admission to the Ed. D. program (see necessary pieces in Table 2). We scaffold the application process by providing applicants a 23-page "Admissions Guide” that describes the steps of the admissions process, explains our general criteria, and provides specific details about (and examples of) the documents they must submit. The guide is available and posted online during the time that we accept applications, which is generally from mid-October to mid-February. We only admit a cohort in the fall semester; we have thus far enrolled a cohort in 2012, 2013, and we are planning for a 2014 cohort.

\section{[INSERT TABLE 2 HERE]}

Applicants go through a four-stage application process:

1. Applicants must earn admission to the Graduate College. The Graduate College staff ensure that all official transcripts are in place and that degrees are from accredited institutions. (Stage 1)

2. Applications are then reviewed by the program coordinator. The program coordinator looks to see if all materials have been summited and checks if the quantitative measures (GPA, GRE, etc.) are acceptable. (Stage 2)

3. Once an application has met the Department's minimal standards, it gets a full review by at least two tenured or tenure-track faculty members, which results in scores and a ranking of each applicant. (Stage 3)

4. The top third of the applicants are invited to participate in two kinds of interviews: a timed, asynchronous interview comprised of short-answer questions and an asynchronous video interview where applicants must answer a series of relevant questions. (Stage 4). Given the time involved and scheduling concerns (for faculty and applicants alike), we do not conduct phone interviews of candidates.

The following is our rationale for each of the extra items that we require.

\section{Prior Degrees}

We prefer that an applicant's master's degree has been completed in Educational Technology or a closely related field, but we consider applicants from all educational backgrounds. The master's degree does not have to have been completed within a certain time before starting doctoral studies, and we do not do a "bachelor's to doctorate" program.

\footnotetext{
${ }^{1}$ One can be accepted into the Graduate College without gaining admission to a particular program, allowing one to take graduate courses but these would not apply to a degree. If accepted into a particular masters or doctoral program at a later time, up to nine hours taken previously could be counted toward the program.
} 
This is an author-produced, peer-reviewed version of this article. The final, definitive version of this document can be found online at TechTrends, published by Springer. Copyright restrictions may apply. doi: 10.1007/s11528-014-0766-1

Additionally, we would like for people to have completed at least some graduate courses online. Our preference for those with a degree in the field and online experiences gives us some confidence that the person is aware of issues in the field, has a commitment to further studies, and does not need to overcome the challenges that face those studying at a distance, such as negotiating issues of psychological distance (Moore \& Kearsley, 2011).

Many applicants in the final selection pool have an academic preparation more closely aligned to courses we offer, but our perspective is that we want to be open to a diverse pool of candidates. For example, within our current cohorts, we have students with graduate degrees in engineering, educational leadership, business, and health care. Interest from outside the field is not necessarily unique to Boise State. Golde and Walker (2006) point out that only one third of "students starting a doctorate in Education have an undergraduate degree in education" (p. 246).

The openness to other degrees is beneficial in that it helps attract excellent prospects from many professional fields. The drawback, though, is that we have to carefully evaluate applications to ensure that a person is not simply seeking a convenient, flexible way to complete a doctoral program. Based on common questions we are asked, it is clear that some applicants are interested in our program not because it is a terminal degree in Educational Technology, but because they have two driving needs: (a) completing a terminal degree to maintain employment or be upgraded in a current position, and (b) completing the degree in a way that is maximally flexible and convenient. Part of the reason we require so many pieces to be submitted for the application is to have overlapping evidence that ensures we select students prepared for and committed to completing the work necessary to earn the degree and who, at the same time, benefit us and other students with the energy, passion, and networks.

\section{Grade Point Average}

Grade point average (GPA) is a common admission criteria (Colarelli, Monnot, Ronan, \& Roscoe, 2012). Our standard is that applicants have at least a 3.00 for graduate work (preferably a 3.50) and a 3.00 for at least half of their undergraduate work (preferably a 3.00 total). A set of high GPA's is not, in and of itself, a factor that ensures selection, and lower GPA's do not automatically exclude one from consideration. Research on GPAs indicates why it is not an automatic selection factor.

First, studies suggest that grades in college have increased over the years (Eiszler, 2002; Sabot \& Wakeman-Linn, 1991). This might be even more apparent in the field of Education. One study on grade inflation in a teacher education program reported that $97 \%$ of students received an "A" (Nikolakakos, Reeves, \& Shuch, 2012). Some have suggested that there is even less variance in course grades in graduate school (Kohn, 2002), and this is borne out by our own admission statistics. We still find that GPA gives us a basic idea of how students have performed in the past, but in the case of low GPA's we consider the field of study. For example, a student who has majored in a science, engineering, math, or health science field may well have a low undergraduate GPA (below 3.0). Given the overall lower GPA's in these fields (Drew, 2011), it is important to consider the rigor of the studies and the 'culture' of such programs as part of the decision process.

\section{Graduate Record Exam (GRE)}

Prospective students regularly question the need to take the GRE - it is expensive, scheduling an opportunity to take it is not easy, and more often than not it gives rise to test or performance anxieties. Though the GRE is not a perfect indicator of performance in graduate studies and has its share of valid critics (see "Estimating the effect," 1998; Jaschik, 2007; Scheuneman, 1985), research suggests it is an effective predictor of student success in graduate school (Burton \& Wang, 2005; Fu, 2012; Kuncel et al., 2010). According to Kuncel et al. (2010), the exam is "effective for admission decision making for both master's- and doctoral-level work and should be incorporated in the application process for both degree levels. Specifically, the GRE has both a comparable and useful predictive validity for master'sand doctoral-level programs” (p. 347). Ultimately, GRE scores help us differentiate between applicants who, by all other measures of the application, appear to be quite nearly equal in terms of academic potential. Our general guidance, based on the many applications we have seen and examining those selected for previous cohorts, is that an applicant needs to have scored in the $33^{\text {rd }}$ percentile at minimum, and in the $50^{\text {th }}$ percentile or higher to be competitive. This does not mean that applications with scores below that mark are automatically excluded - they are not - but it does mean that eligibility for Stage 3 of application review requires a closer inspection of materials. 


\section{Letter of Application}

The letter is a critical part of the application, as it serves three purposes. First, it is one of two writing samples that allow us to assess a person's writing ability; it also demonstrates how well she or he pays attention to detail (e.g., proofreading). Secondly, it helps us determine if the applicant's area of interest is a good match with the interests of our faculty members, which is important as only full-time faculty members serve as research advisors - we do not use adjuncts to fill this essential role. Finally, the letter provides insight as to whether a person is a good fit for a program focused on professional practice, innovativeness, and leadership in Educational Technology. In the letter, applicants are asked to address their career goals and how the degree factors into these goals, their professional experiences and the relevance of those experiences to doctoral study in Education, their interest in a particular area of specialization within Educational Technology, and questions they would like to specifically research. Because these letters take time to read, we only read those of applicants who have moved to the third stage of the review process.

\section{Résumé / Curriculum Vitae}

We ask all applicants to submit a résumé that has been formatted in a very specific way, which allows faculty reviewers to see a consistent format for each one they examine. The admissions guidelines specify the format and also provide an example, so here again, we consider an applicant's ability to attend to detail. The résumé is more closely inspected in the third review stage, but since it gives background information about prior experiences in the field of Educational Technology, it helps us make an initial determination as to the applicant's overall preparedness and fit (Stage 2). While many applicants might not have a prior degree in the field, they might have experience working in various capacities in it. Given our perspective on a degree program that focuses on the practitioner, and the desire to help prepare those who can lead and innovate, it is useful to see evidence for an applicant's potential to do so.

\section{Scholarly Paper}

As all who have completed a doctoral degree in social sciences can attest, projects in doctoral courses involve a good deal of writing. The capstone experience is the dissertation, which requires excellent writing and synthesis; it is a stage where many graduate students struggle and where they need the most advising. Kumar and Johnson (2014) found that writing the dissertation was one of the hardest parts for online doctoral students. The submission of a scholarly paper in the admissions process puts applicants on notice that writing ability is an important consideration in the selection process. We encourage people to submit substantive papers - for example any peer-reviewed work they might have authored or co-authored, or a major work like a master's thesis. These types of submissions, however, are rare to find among applications. More often than not, the paper is a longer one they have written for a graduate course. No matter what is submitted, we are looking for writing that is indicative of a solid understanding of issues in Education or Educational Technology, the ability to write in a clear academic voice, and the ability to cite and reference works. No faculty member or research committee member relishes the idea of serving as a writing tutor, so these skills are important to identify before a person is offered admission.

\section{Academic References}

Each person who applies must provide the names and contact information for three persons, each of whom should have direct knowledge of the applicant's ability, potential, and demeanor. We prefer for applicants to submit names of faculty members with whom they may have worked in a previous graduate program, but this is not always possible. Our own approach is for the referee to complete a web-based form rather than submit a letter. Reference letters are difficult to interpret because the approach each reference-provider takes is unique. The data we gather through the online reference form (a survey we create using the university's online survey tool) are aggregated for each applicant and used as part of the data in the second stage of review. If an applicant has any negative reviews, she or he does not go on to a full review (Stage 3). All things considered, we have found references to be important to screen out those who may not be a fit for a doctoral program (and this has happened). Given that so many scores or letters are overwhelmingly positive, it is not a piece of the application materials that provides a great deal of insight for our selection process. 
This is an author-produced, peer-reviewed version of this article. The final, definitive version of this document can be found online at

TechTrends, published by Springer. Copyright restrictions may apply. doi: 10.1007/s11528-014-0766-1

\section{Short Answer Questions and Video Responses}

Doctoral programs have a long history of interviewing prospective students and we see the value in interviewing as well. However, as all who interview candidates can attest, doing so takes a great deal of time - not the least of which is for the logistics of the interviews themselves. To reduce load on faculty, who quite simply do not have the time to interview dozens of people, we have developed a two-part, asynchronous interview process. Only the top third of applicants arising out of the full review stage are invited to participate in this part of the process (this is Stage 4, which we call the "interview" although it does not have a phone or synchronous aspect). The applicants are given one week to submit the interview, and both parts are submitted at the same time (short answer and video). We have developed a set of guidelines for the interview process so that candidates know what to expect. In Part 1, they must respond to a series of timed, short-answer questions (we do not release these ahead of time) that are provided to them in an online form. In Part 2, they must create and upload a video interview.

\section{The purpose of Part 1, the Timed, Short-Answer Qualitative Responses}

(TSAQR), is to get an applicant's first impressions, which in some way replicates what happens in a synchronous interview. Synchronous interviews, conducted in traditional programs, tend to be short (no more than 20 minutes long) interviews conducted on the phone. Since the interviewee typically does not know the questions ahead of time, her or his responses are extemporaneous. Therefore, the goal of the TSAQR is to get a glimpse at what might come "off the top of someone's head." The hope is that we will be able to see what information can be brought forth quickly, with the assumption that the answer is representative of something much deeper. The TSAQR consists of ten questions designed to be answered in two minutes or less. Another two questions are designed to be answered in five to seven minutes, and these tend to be case scenarios. The responses allow us to see evidence of experience, systemic thinking, creativity, writing ability, etc. We continue to try different formats and question types, as some have been useful, whereas others we have used seemed to solicit answers that are too generic.

The second part, the Video Questionnaire has two goals: First, we want to see evidence of an applicant's experience and passion as he or she answers the questions (which are provided ahead of time). Second, we feel that a candidate for Educational Technology should be able to produce and upload a short digital video as evidence of technological capacity. The instructions make clear that the video is not to be overly produced (in fact, we discourage it), and its total length must be no more than 10 minutes. In the past, we have asked questions that may mirror elements of the letter of application, but we also ask applicants to comment specifically on aspects about Educational Technology that might not otherwise be addressed. Examples of questions we have asked include:

- “Tell us why you want a doctorate in this field?” or

- "Which issues in Educational Technology do you think are the most pressing, and why?” or

- "Some doubt that technology has much impact in the classroom. How would you respond to this assertion?"

From time to time we ask questions that are not directly related to the field, but are more conversational in nature responses a person would not necessarily have to rehearse, such as "Tell us what kind of music you like, and why." In these other questions, we are not judging the content, but intangibles like passion or creativity or reflection. It is expected that applicants might have rehearsed answers to these questions, but we strongly encourage them to speak naturally and not read their response. We have found the videos to be useful as they have helped us more closely consider some candidates that seemed very good on paper but may have lacked the "edge" that made them stand out. And, in other cases, we have seen people who appeared to be very good in terms of qualifications, but whose video responses or overall demeanor showed that she or he was not what we felt would be the best for our program. Other advantages of the video interview include: taking (some) pressure off applicants as they have a chance to prepare responses ahead of time, and from a logistics standpoint, these video interviews allow faculty to review them on their own time and as frequently as they might like.

\section{The Program Selection Process}

As noted previously, admission to the doctoral program is a four-stage process, beginning first with acceptance into the Graduate College. Stage 2 is essentially a "quantitative easing" stage, where we evaluate only the aspects of the application that make a person eligible for full review. In Stage 2, we check to see if all materials have been submitted (and completed correctly), if GPA and GRE scores are within an acceptable range, and if the reference scores and/or 
This is an author-produced, peer-reviewed version of this article. The final, definitive version of this document can be found online at TechTrends, published by Springer. Copyright restrictions may apply. doi: 10.1007/s11528-014-0766-1

letters are positive. The purpose is to reduce the number of people who faculty must review in Stage 3. In the previous two cohorts, this has resulted in approximately $33 \%$ of the applicants who do not move on, which puts less of a burden on faculty reviewers - especially since portfolio reviews for our master's program students is often being done at the same time, and various professional conferences are being held.

The program coordinator and some staff members put a good deal of work to prepare for Stage 3 of the review process. Applicants' materials are put in individual folders in Google Drive; Boise State University was an early adopter of Google Apps for Institutions, and we currently retain this system for email, document sharing, etc. The materials include the Graduate College application, the letter of application, the résumé, the scholarly paper, and any materials or scores from the references. Faculty members (tenure-track, or lecturers with a terminal degree who wish to participate) are then given access to a spreadsheet with the data for all applicants, and each person has his or her own spreadsheet (created and shared by the program coordinator) that allows for the input of their scores based on a common rubric. Each faculty member is randomly assigned to rate the application materials of approximately $30 \%$ of the Stage 3 pool; each applicant gets reviewed by no fewer than three faculty members, which includes the program coordinator who reviews all applications. After the two to three weeks set aside for faculty to complete their reviews, the scores are tallied. Those applicants who are in the top 30 (or so), are then asked to take part in the online, asynchronous interview stage (Stage 4). After the week it takes applicants to complete the interview form and video, faculty are again asked to rate the interview materials, and again, each applicant has at least three total faculty reviewers. A rubric for reviewing the interviews is less prescriptive than the one used in Stage 2, but a score is recorded on a shared form.

Finally, after the scores from the Stage 3 and Stage 4 reviews are aggregated for each applicant, the list is put in rank order. The top 20 (or so) candidates who rank at the top of that list and about whom faculty have indicated they have a desire to advise are then offered admission into the program. The letter comes from the Graduate College directly after the program coordinator has indicated the department's decision in the online application system. Once notified, applicants who are accepted have approximately one week to indicate whether or not they will start in the fall semester. If more than an acceptable number decline (we have not yet faced this situation), then it is possible that offers would be made to any who were outside the pool of top candidates identified. A person who declines admission can delay his/her start by up to one year.

\section{Lessons Learned}

There is no doubt that our current system can be time consuming, though most of the current work falls on the program coordinator, who gets a reduction in teaching load to contend with the administrative details. Although the amount of time individual faculty have to spend is generally estimated not to be more than 10-15 hours total, it is nevertheless yet one more service obligation during an otherwise busy time. In the past, we have sent a post-application survey to applicants seeking their input about the process. The data showed an overwhelmingly positive response, but we understand that this does not necessarily mean that our approach is optimal. For example, programs with speedier processes in place may have some competitive advantage in being able to notify applicants more quickly. Additionally, students may feel greater confidence if they do not feel they are undergoing intense scrutiny.

While we are open to change and look for ways to improve, we are confident that our process works well in selecting top quality students. It is important for us to get good students at the outset so as to help reduce problems further along in the program. We have already seen that our current system does not mitigate early attrition, but we are unsure of its impact at the dissertation stage as none of our students have reached that point. However, the reasons given by those who have dropped the program so far vary, and none are factors that could be accounted for in the selection process.

The most useful lesson learned thus far, though, does not have to do with students we have selected, but those we have not. Without going into a great amount of detail, we have already dealt with one applicant who nearly threatened legal action, because she was not admitted to program. In the end, messages from both the General Counsel's office and Dean of the Graduate College seemed to assuage the demands to know specifics about the reason she was not admitted. The inquiry into the process created a good deal of work for the program coordinator and others, but the saving grace was a very careful system that documented all decisions, showing that the evaluations of applicant materials were applied fairly to all. 
This is an author-produced, peer-reviewed version of this article. The final, definitive version of this document can be found online at

TechTrends, published by Springer. Copyright restrictions may apply. doi: 10.1007/s11528-014-0766-1

Fortunately, the experience with the agitated applicant stands out because it has only happened once to date. Despite the frustrations it caused, the inquiry confirmed the strength and benefits of our system internally, to the College of Education, and to the Graduate College. An entirely online doctoral program faces increased scrutiny, so it is imperative to have systems and policies in place that emphasize the faculty's commitment to both rigor and equality.

\section{References}

Burnett, P. C. (1999). The supervision of doctoral dissertations using a collaborative cohort model. Counselor Education and Supervision, 39(1), 46-52.

Burton, N. W., \& Wang, M. M. (2005). Predicting long-term success in graduate school: A collaborative validity study. [Research report]. Princeton, NJ: Educational Testing Service.

Colarelli, S. M., Monnot, M. J., Ronan, G. F., \& Roscoe, A. M. (2012). Administrative assumptions in top-down selection: A test in graduate school admission decisions. Applied Psychology, 61(3), 498-512.

Dawson, K., Cavanaugh, C., Sessums, C., Black, E. \& Kumar, S. (2011). Designing a professional practice doctoral degree in Educational Technology: Signature pedagogies, implications and recommendations. Journal of Distance Education, 25(3). Retrieved from http://www.jofde.ca/index.php/jde/article/view/767

Drew, C. (2011, November 4). Why science majors change their minds (It’s just so darn hard). New York Times. Retrieved from http://www.nytimes.com/2011/11/06/education/edlife/why-science-majors-change-theirmind-its-just-so-darn-hard.html?pagewanted=all\&_r=0

Eiszler, C. F. (2002). College students' evaluations of teaching and grade inflation. Research in Higher Education, 43(4), 483-501.

Estimating the effect a ban on racial preferences would have on African- American admissions to the nation's leading graduate schools. (1998). The Journal of Blacks in Higher Education, 19, 80-82.

$\mathrm{Fu}, \mathrm{Y}$. (2012). The effectiveness of traditional admissions criteria in predicting college and graduate success for American and international students (Doctoral dissertation, The University of Arizona). Retrieved from http://arizona.openrepository.com/arizona/bitstream/10150/217056/1/azu_etd_11970_sip1_m.pdf

Golde, C. M. (2006). Preparing stewards of the discipline. In C. M. Golde \& G. E. Walker (Eds.), Envisioning the future of doctoral education: Preparing stewards of the discipline (pp. 3-20). Stanford, CA: The Carnegie Foundation for the Advancement of Teaching.

Golde, C. M., \& Walker, G. E. (Eds.). (2006). Envisioning the future of doctoral education: Preparing stewards of the discipline. Stanford, CA: The Carnegie Foundation for the Advancement of Teaching.

Hawley, P. (2003). Being bright is not enough: The unwritten rules of doctoral study. Springfield, IL: Charles C. Thomas.

Jaschik, S. (2007). ETS aborts new GRE. Inside Higher Ed. Retrieved from http://www.insidehighered.com/news/2007/04/03/ets

Kohn, A. (2002). The dangerous myth of grade inflation. Chronicle of Higher Education, 49(11), B7.

Kumar, S., \& Johnson, M. (2014). Research and dissertations: Challenges overcome by online doctoral students. In P. R. Lowenthal, C. S. York, \& J. C. Richardson (Eds.), Online learning: Common misconceptions, benefits, and challenges. Hauppauge, NY: Nova Science Publishers.

Kuncel, N. R., Wee, S., Serafin, L., \& Hezlett, S. A. (2010). The validity of the Graduate Record Examination for master's and doctoral programs: A meta-analytic investigation. Educational and Psychological Measurement, 70(2), 340-352.

Lee, A., \& Danby, S. (Eds.). (2012). Reshaping doctoral education: International approaches and pedagogies. New York, NY: Routeldge.

Levine, A. (2005). Educating school leaders. Washington, DC: The Education Schools Project. Retrieved from http://www.edschools.org/pdf/Final313.pdf

Mason, M. A. (2012). The future of the Ph.D. The Chronicle of Higher Education. Retrieved from http://chronicle.com/article/The-Future-of-the-PhD/131749/

Moore, M., \& Kearsely, G. (2011). Distance education: A systems view of online learning, $3^{\text {rd }}$ Ed. Stamford, CT: Cengage.

Nikolakakos, E., Reeves, J. L., \& Shuch, S. (2012). An examination of the causes of grade inflation in a teacher education program and implications for practice. College and University, 87(3), 2-13.

Park, J.-H., \& Choi, H. J. (2009). Factors influencing adult learners' decision to drop out or persist in online learning. Educational Technology \& Society, 12(4), 207-217. 
Perry, J. A., \& Imig, D. G. (2008). A stewardship of practice in education. Change, 40, 42-48.

Perry, J. A., \& Imig, D. G. (2010). Final report: The Carnegie Project on the Education Doctorate, 2007-2010. [White paper]. Retrieved from CPED Initiative: http://cpedinitiative.org/files/CPED_Final_Report_2010\%20copy\%202.pdf

Sabot, R., \& Wakeman-Linn, J. (1991). Grade inflation and course choice. Journal of Economic Perspectives, 5(1), 159-170.

Scheuneman, J. (1985). Exploration of causes of bias in test items. (Research Report, 85-42). Princeton, NJ: Educational Testing Services.

Shulman, L. S., Golde, C. M., Bueschel, A. C., \& Garabedian, K. J. (2006). Reclaiming education’s doctorates: A critique and a proposal. Educational Researcher, 35(3), 25-32.

Stavredes, T. (2011). Effective online teaching: Foundations and strategies for student success. San Francisco, CA: Jossey-Bass.

Walker, G. E., Golde, C. M., Jones, L., Bueschel, A. C., \& Hutchings, P. (2008). The formation of scholars: Rethinking doctoral education for the Twenty-first century. Stanford, CA: The Carnegie Foundation for the Advancement of Teaching. 
Table 1. Ed.D. in Educational Technology Requirements at Boise State University

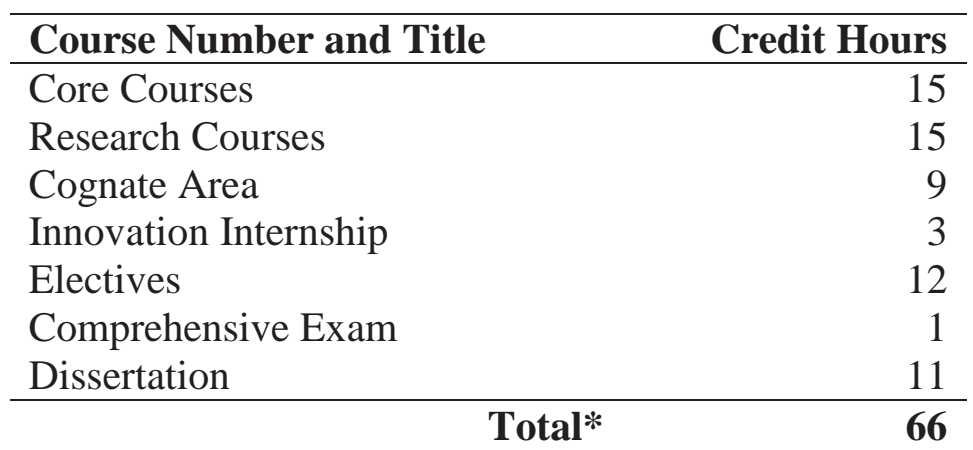

* The Graduate College at Boise State University allows a student to transfer courses for up to $1 / 3^{\text {rd }}$ of the total credit hours for the program. All transfer course requests must first be approved by the program faculty before being approved by the Graduate College.

Table 2. Items Required for Initial Application to the Graduate College and Ed.D./EdTech Program at Boise State University

\begin{tabular}{llc}
\hline Application Materials & $\begin{array}{l}\text { Required by } \\
\text { the Graduate } \\
\text { College }\end{array}$ & $\begin{array}{c}\text { Additional Items } \\
\text { Required by } \\
\text { EdTech }\end{array}$ \\
\hline $\begin{array}{l}\text { Official transcripts from all institutions from which } \\
\text { one earned graduate and undergraduate credit }\end{array}$ & $\mathrm{X}$ & $\mathrm{X}$ \\
\hline $\begin{array}{l}\text { Official Graduate Record Exam Scores (taken within } \\
5 \text { years of application deadline) }\end{array}$ & $\mathrm{X}$ \\
\hline $\begin{array}{l}\text { Completed Graduate College Application form } \\
\text { Written Letter of Application (2 pages) }\end{array}$ & $\mathrm{X}$ \\
\hline $\begin{array}{l}\text { Short-form Résumé / C.V. } \\
\text { Sample of scholarly writing }\end{array}$ & $\mathrm{X}$ \\
\hline $\begin{array}{l}\text { Names and contact information for three references } \\
\text { that can attest to academic skill }\end{array}$ & $\mathrm{X}$ \\
\hline $\begin{array}{l}\text { Thternational students only; within two years of } \\
\text { applion deadline) }\end{array}$ & $\mathrm{X}$ \\
\hline
\end{tabular}

